\title{
Многоцветная многофотонная микроскопия на основе наносекундного источника суперконтинуума
}

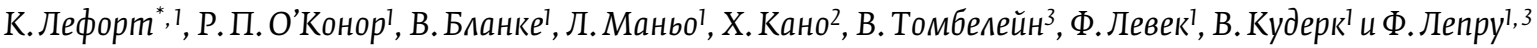 \\ 1 Universite de Limoges, CNRS UMR, claire.lefort@xlim.fr, Лимож, Франция \\ ${ }^{2}$ Институт прикладной физики университета Цукубы, Цукуба, Япония \\ 3 Leukos Innovative Optical Systems, Лимож, Франция
}

\begin{abstract}
Многоцветная многофотонная микроскопия впервые экспериментально продемонстрирована на спектральной полосе возбуждения 300 нм (полная ширина на высоте половины максимума) благодаря использованию наносекундного источника суперконтинуума (СК) в компактном и простом исполнении с низкой частотой повторения импульсов. Интерес к такой широкой спектральной полосе, никогда не демонстрировавшейся до сих пор, подчеркивается in vivo: получены изображения клеток глиомной опухоли, стабильно экспрессирующих еGFP, привитых на мозг мыши и ее сеть кровеносных сосудов, меченных Texas Red ${ }^{\circledR}$. Эти два флуорофора имеют спектральную полосу, охватывающую все доступные 300 нм. Параллельно аналогичное качество изображения получают на образце мышечной ткани мыши in vitro при возбуждении этим наносекундным источником СК или классическим высокочастотным, фемтосекундным и квазимонохроматическим лазером. Это открывает путь для (i) простой и очень полной биологической характеристики, никогда не выполнявшейся до настоящего времени с многофотонными процессами, (ii) множественных средств контрастирования в нелинейном изображении, допускаемые использованием многочисленных флуорофоров и (ііi) других многофотонных процессов, таких как трехфотонные.
\end{abstract}

Ключевые слова: многофотонная микроскопия, нелинейная визуализация, наносекундный источник суперконтинуума, многоволновая визуализация

\section{1. ВСТУПЛЕНИЕ}

Многофотонная микроскопия (МФМ) - широко распространенный метод для получения изображений с высоким разрешением, трехмерных и глубоких изображений живых или иссеченных тканей, включающий нелинейные процессы [1], такие как двухфотонная флуоресценция (ДФФ) и генерация второй гармоники (ГВГ) [2]. Скорость излучения ДФФ определенного флуорофора зависит от параме- тров возбуждающего лазера [3-6]: длительности импульса $t$, частоты повторения $f$ и средней мощности $\overline{\mathrm{P}}$ - и следует закону, связанному с импульсной пиковой мощностью $\hat{\mathrm{P}}$ :

$$
\psi \propto \eta \hat{P} \propto \frac{\bar{P}^{2}}{f_{\tau}},
$$

где $n$ - постоянная величина, зависящая от длины волны возбуждения, двухфотонного сечения флюо-

Примечание редактора: статья из журнала дана в переводе с согласия авторов и в полном согласии с условиями открытого доступа на условиях лицензии Creative Commons Attribution-Non Commercial-No Derivs, которая разрешает использование и распространение на любом носителе при условии, что оригинальная работа должным образом цитируется.

Multicolor multiphoton microscopy based on a nanosecond supercontinuum laser source.

Claire Lefort ${ }^{*}, 1$, Rodney P. O'Connor ${ }^{1}$, Véronique Blanquet ${ }^{1}$, Laetitia Magnol ${ }^{1}$, Hideaki Kano², Vincent Tombelaine ${ }^{3}$, Philippe Lévêque ${ }^{1}$, Vincent Couderc ${ }^{1}$, and Philippe Leproux ${ }^{1,3}$

e-mail: claire.lefort@xlim.fr

Université de Limoges, CNRS UMR 7252, Labex “Sigma-Lim”, INRA UMR 1061, F-87000 Limoges, France

Institute of Applied Physics, University of Tsukuba, 1-1-1 Tennodai, Tsukuba, Ibaraki, 305-8573, Japan

LEUKOS Innovative Optical Systems, 37 rue Henri Giffard, Z.I. Nord, 87280 Limoges, France

Received 23 October 2015, revised 19 December 2015, accepted 6 January 2016, published online 15 February 2016. DOI 10.1002/jbio.201500283 
рофора и характеристик объектива. Учитывая уравнение (1), несколько комбинаций между $\mathrm{P}, t$ и $f$, вероятно, порождают многофотонные процессы.

На протяжении многих лет квазимонохроматические МГц, фемтосекундные лазеры в ближнем инфракрасном диапазоне (БИК) и в основном титан-сапфировые (Ti:Sa) источники преимущественно используются для МФМ [7]. Эти источники имеют ряд преимуществ: высокую частоту повторения, низкую энергию импульсов, большую спектральную перестраиваемость и высокую среднюю мощность. Другие монохроматические источники также использовались незначительно, такие как наносекундные [8], пикосекундные [4] и субпикосекундные лазеры [9]. Различные длительности импульсов от 100 фс до 100 пс с постоянной частотой повторения позволяют получать аналогичные многофотонные взаимодействия [10-12] при условии достаточной средней мощности и соблюдения уравнения (1).

Помимо временного аспекта источника возбуждения, его спектральные свойства имеют свое значение в МФМ и могут привести к определению трех критериев: (i) спектральная перестраиваемость позволяет возбуждать большую панель экзогенных или эндогенных флуорофоров; (ii) широкий спектр имеет возможность отображать несколько флуорофоров одновременно (многоцветный МФМ), даже те, которые имеют очень далекие спектры двухфотонного поглощения (ДФП); (iii) сформированный спектр позволяет в лучшем случае адаптироваться к спектру ДФП флуорофора. Таким образом, сверхширокополосные источники, называемые источниками суперконтинуума (CK), нашли свое место в МФМ [13]. Такие источники обычно основаны на спектральном уширении фемтосекундных импульсов в фотонно-кристаллическом волокне (ФКВ), связанном с предшествующим или последующим сложным и дорогостоящим этапом формирования импульсов [14]. Эти высокочастотные фемтосекундные источники, имеющие спектральную полосу в лучшем случае 200 нм, были использованы для селективной ДФФ-визуализации специфических флуорофоров [15-17] и для многоцветных МФМ [18-21]. Сообщалось также о реализации источника СК на основе пикосекундного лазера с дополнительными оптическими усилителями для демонстрации биоимиджинга ДФФ [22]. Насколько нам известно, ни один лазерный источник, удовлетворительно отвечающий трем ранее установленным критериям, не был выявлен для МФМ.

В данной публикации мы впервые экспериментально демонстрируем способность низкоско- ростного, простого и компактного наносекундного источника СК генерировать многоцветные многофотонные процессы. Это иллюстрируется изображениями биологических образцов, полученных с беспрецедентной полосой возбуждения 300 нм в БИК спектре. В первой части доказательство принципа этого нового метода показано на резецированном образце мышечной ткани мыши. Полученные изображения ДФФ и СК сравниваются с изображениями, полученными с помощью классического источника возбуждения Ti : Sa. Для понимания аналогичного качества изображения проводится дальнейшее исследование пиковых уровней мощности. Во второй части мы выделяем адаптированное и сопоставимое разрешение в микронном масштабе, чтобы наблюдать ожидаемую чередующуюся структуру мышцы. Наконец, с помощью наносекундного возбуждения СК нам удалось продемонстрировать в естественных условиях многоцветный МФМ путем визуализации опухолевых клеток, имплантированных в мозг мыши* одновременно с сетью кровеносных сосудов. Простым способом спектр СК формируется и адаптируется к спектрам ДФП обоих используемых флуорофоров, покрывая всю полосу пропускания 300 нм СК с их максимумами, разделенными 150 Нм, что приводит к оптимизированному излучению ДФФ.

\section{2. УСЛОВИЯ ЭКСПЕРИМЕНТА}

Наносекундный СК лазер является результатом спектрального уширения в одномодовом ФКВ усиленного модулированного лазерного диода с центром в 1550 нм (1 нс, 10 мкДж, 250 кГц). ФКВ имеет длину 1 м и легированный Gе кремнеземный сердечник с длиной волны нулевой дисперсии, близкой к 1400 нм. Таким образом, он накачивается в режиме аномальной дисперсии, что приводит к генерации ка примерно от 600 нм до 2400 нм. Результирующая длительность импульса источника ка составляет 1 нс при общей средней мощности 1 Вт. Спектр фильтруется между 700 нм и 1000 нм с помощью набора фильтров высоких и низких частот. В результате средняя мощность 120 МВт заводится в вертикальный многофотонный микроскоп

Использование животных было одобрено этическим комитетом по уходу за животными (регистрационный номер: 15-2014-15). Весь уход за животными и экспериментальные процедуры проводились в соответствии с французским декретом № 2013-118 от 1 февраля 2013 г. NOR: AGRG1231951D в соответствии с руководящими принципами европейского сообщества (директива 2010 / 63/UE по уходу и использованию лабораторных животных). 
(BX61WI, компания Olympus, Япония), состоящий из системы сканирования, водно-иммерсионного объектива микроскопа (XLPLN25XWMP, компания Olympus, Япония), двух дихроичных зеркал и двух фотоэлектронных умножителей (ФЭу) в сочетании с полосовыми фильтрами (575-630 нм; 390-420 нм на ДФФ и ГВГ каналы соответственно). Зеркальное отражение позволяет переключаться между возбуждениями от источника СK к фемтосекундному лазеру Ti:Sa (Chameleon Ultra II, Coherent, США; 150 фс, 10 нм, 680-1080 нм, 80 МГц, 4 Вт). На рис. 1А показана экспериментальная установка.

Изображения могут быть получены из одного или другого источника без перемещения объектива микроскопа или образца. Боковое и осевое разрешения рассчитаны соответственно при 0,4 мкм и 1,3 мкм с учетом длины волны возбуждения 810 нм.

\section{3. МФМ С НАНОСЕКУНДНЫМ ИСТОЧНИКОМ СК}

Образец вырезают из мышцы ноги мыши, имеющей волокнистую структуру [23]. Каждое из волокон состоит из дисков миозина и актина, наложенных попеременно и перпендикулярно оси волокна. Миозиновая организация представляет собой не центросимметрическую структуру, дающую начало ГВГ [24]. Присутствие альфа-актинина, цитоскелетного белка, связывающего актин, маркируется здесь иммуногистохимией с помощью вторичного антитела, связанного с Alexa Fluor ${ }^{\circledR} 546$. Следовательно, полученный образец идеально подходит для обоих средств контрастирования: ДФФ Alexa Fluor ${ }^{\circledR}$ 546, выявляющий присутствие альфаактинина одновременно с ГВГ из структуры миозина. Отрезок 4 мкм фиксируется на предметном стекле микроскопа. На рис. 1b показаны спектры интенсивности обоих лазерных источников, измеренные на выходе объектива микроскопа, а также спектры ДФП Alexa Fluor ${ }^{\circledR} 546$, eGFP и Texas Red ${ }^{\circledR}[25-$ 27]. Лазер Ti: SA сосредоточен на длине волны 810 нм, максимум поглощения Alexa Fluor ${ }^{\circledR} 546$.

На рис. 2 показаны изображения мышечной ткани размером $500 \times 500$ мкм² $^{2}$ полученные при освещении CK и Ti:Sa в случае ДФФ, ГВГ и обоих в сочетании с одинаковой интенсивностью цвета (время задержки пикселя 100 мкс). Как и ожидалось, волокнистая структура выявляется ДФФ (актином) и ГВГ (миозином) независимо от источника возбуждения, что доказывает способность СК-лазера давать удовлетворительные многофотонные изображения. Поверхность образца, которая визуализирована с CK источника (рис. 2a), выглядит крупнее, чем на

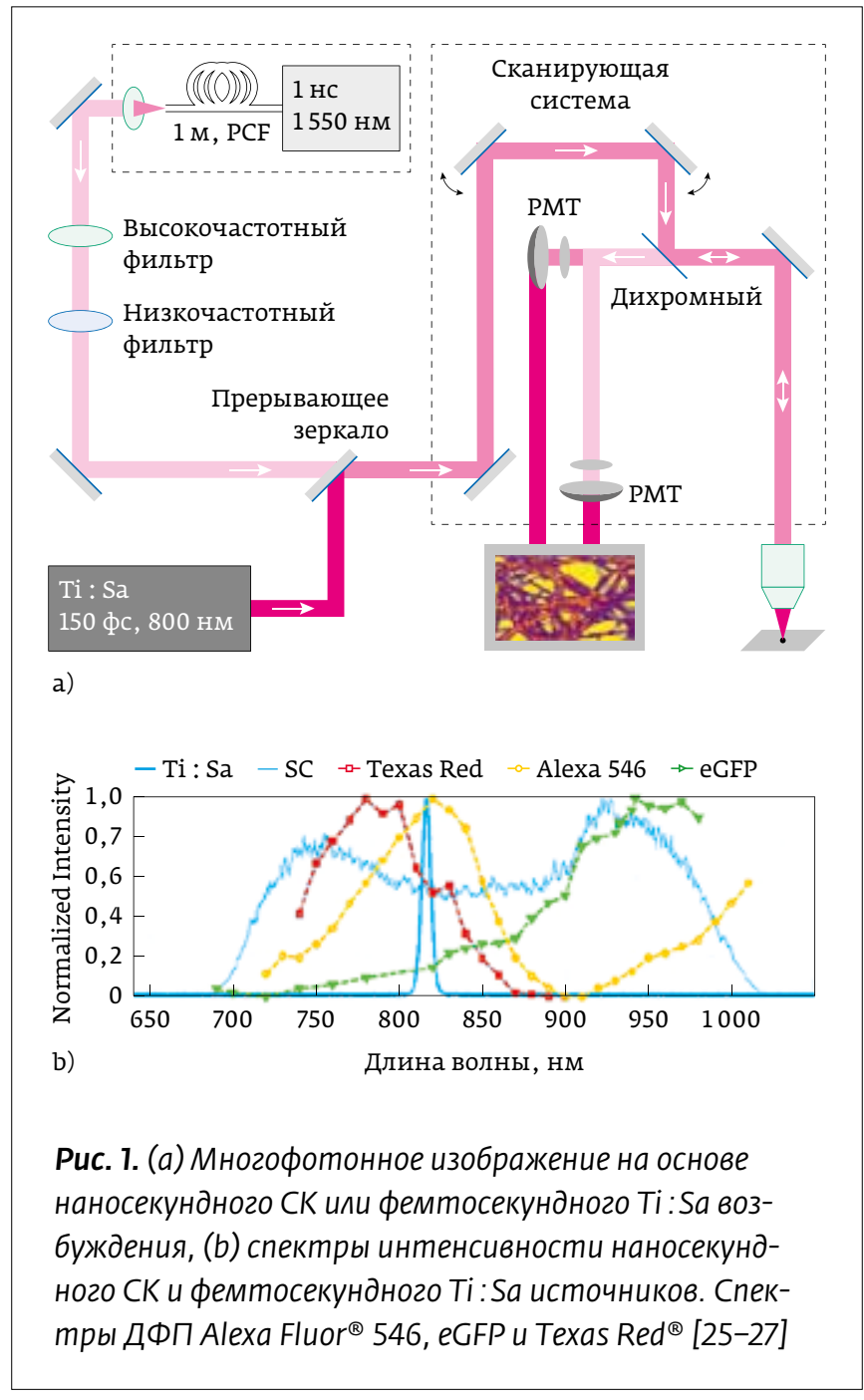

кристалле Ti:SA лазера (рис. 2d), особенно в отношении ДФФ. Интересно, что изображение ДФФ при возбуждении СK менее чувствительно к случайной плоскостности поверхности образца, возникающей в результате операций иссечения, резки и фиксации. Это различие является результатом распространения фокуса в глубине из-за цветности объектива с 300 нм спектральной полосой пропускания SC. Более лучшее осевое разрешение логически получено с лазером Ti:Sa. C другой стороны, изображение ГВГ, полученное с помощью источника CK (рис. 2б), более контрастно, поскольку только 60 нм из диапазона СK (780-840 нм) соответствуют генерации сигнала $\mathrm{SH}$, который обнаруживается между 390 нм и 420 нм.

Начиная с этого предварительного сравнения, оцениваются и сравниваются доступные пиковые мощности обоих источников возбуждения. ФКВ источника СK накачивается в режиме аномальной дисперсии, что приводит к уширению спектра 


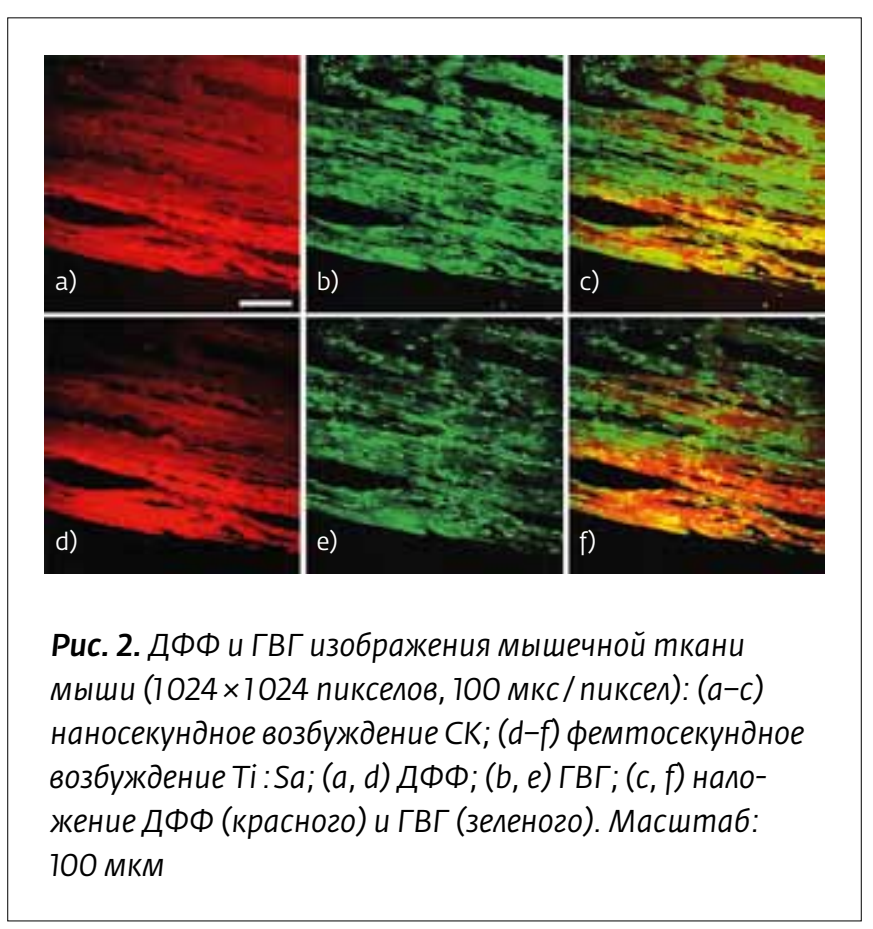

в сторону более длинных длин волн за счет модуляционной неустойчивости, генерации солитонов и сдвига собственной частоты солитонов [28]. В области нормальной дисперсии спектральное уширение индуцируется четырехволновым смешением между солитонами и дисперсионными волнами [29], которые, кроме того, испытывают солитонные столкновения, кросс-фазовую модуляцию и эффект комбинационного рассеяния. После распространения в $Ф \mathrm{~KB}$, с чередованием временного сжатия и растяжения, начальная наносекундная монохроматическая волна накачки преобразуется в широкополосную наносекундную СК, состоящую из некогерентных коротких импульсов, пиковая мощность которых может составлять от нескольких десятков ватт до нескольких киловатт [30]. Эффективность преобразования лазера накачки 1550 нм (10 мкДж, 10 кВт, 2,5 ВТ) в используемый БИК диапазон (700-1000 нм) составляет 5\%, что приводит к получению высокоструктурированного наносекундного импульса с суммарной энергией 500 нДж и пиковой мощностью 0,5 кВт (рассматриваемой в среднем по всем субимпульсам), соответствующей 125 МВт средней мощности при 250 кГц. Результирующая энергия, пиковая мощность и средняя мощность, подаваемые на цель, составляют соответственно 370 нДж, 370 Вт и 92 мВт против 70 пДж, 460 Вт и 5,5 мВт для фемтосекундного лазера Ti : Sa. Таким образом, средняя пиковая мощность источника СК всего в 1,24 раза ниже, чем у лазера Ti:Sa.
Экспериментальный результат, показанный на рис. 2, был в конечном счете ожидаемым, учитывая, что пиковая мощность является основным физическим параметром источника возбуждения, ответственного за генерацию многофотонных процессов. Кроме того, в течение всего эксперимента не наблюдалось никаких фоторазрушений, независимо от источника излучения лазера. Основываясь на этих наблюдениях, наносекундный источник SC вполне способен генерировать процессы ДФФ и ГВГ таким же образом, как и лазер Тi : Sa.

\section{4. СРАВНЕНИЕ КОНТРАСТА}

Различные вклады актина и миозина были диссоциированы путем увеличения области интеpeca (ROI) в микронном масштабе, показанном на рис. 3. Микронная организация мышечных волокон очевидна независимо от выбранного источника лазерного излучения. Нити актина и миозина, выявленные соответственно ФКВ и ГВГ, организованы в диски, наложенные попеременно и перпендикулярно оси волокна. Я диски (актин) и диски (в основном миозин) хорошо определены. Здесь отчетливо виден низкий контраст изображения ДФФ, полученного с источником СК (рис. За), по сравнению с результатом, полученным с помощью лазера Ti: Sa (рис. 3B). Изображение ГВГ, полученное с помощью источника СК, имеет высокую контрастность и качество, как видно из рис. $3 \mathrm{~b}$.

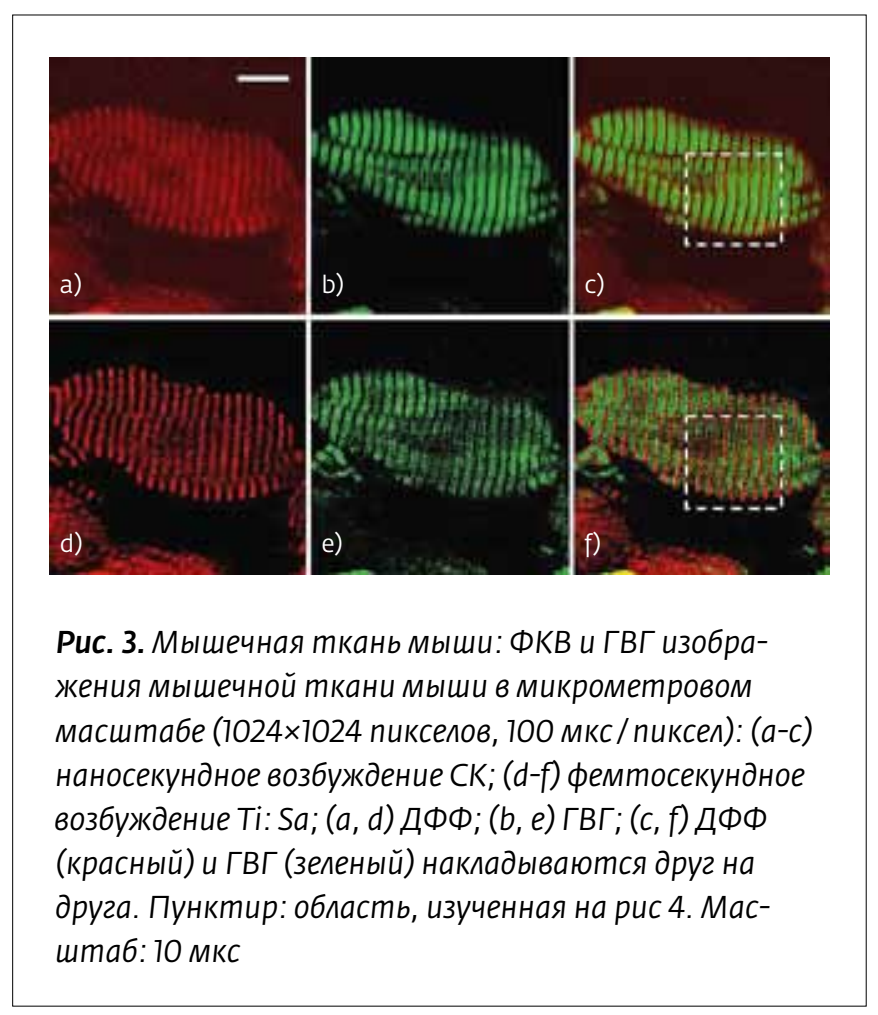


Профили интенсивности ДФФ и ГВГ были построены по линии, изображенной на рис. 4а и 4c, для количественной оценки контраста изображения, исходя из масштаба области, изображенной на рис. $3 \mathrm{c}$ и $\mathrm{f}$ соответственно. На рис. 4b и d соответственно показаны профили интенсивности в произвольной единице для лазеров CK и Ti: Sa.

Чередование актина и миозина с противофазными профилями четко идентифицировано, что подчеркивает адаптирован ${ }^{-}$ ное боковое разрешение многофотонного микроскопа независимо от источника лазера с периодичностью 2,2 мкм, рассчитанное в течение шести пери ${ }^{-}$ одов. Рассчитанный средний контраст для изображения ФКВ при возбуждении СK (рис. 4а) составляет всего $57,7 \%$, что согласуется с предыдущими наблюдениями. Для ФКВ на рис. 4с и для ГВГ на рис. 4а и с контраст близок к 100\%. Наконец, двойная пиковая структура сигнала ГВГ, особенно заметная при возбуждении СК, может быть объяснена наличием дисков Н в центре дисков А.Высказывается гипотеза, что снижение эффективности ГВГ в этой области обусловлено особым молекулярным расположением.

Низкий контраст изображений ДФФ (рис. 2a, 3a, 4а) может быть улучшен за счет ограничения распространения фокуса в глубине. Это может быть реализовано (i) путем уменьшения полосы пропускания СК только до десятков нанометров с помощью фильтрующих / формирующих устройств или - предпочтительно - (ii) путем использования ахроматического объектива в полезном спектральном диапазоне.

\section{5. МНОГОЦВЕТНАЯ МФМ IN VIVO}

Источник СК используется для МФМ, реализованной in vivo на мозге мыши, анестезированной кетамином/ксилазином, где клетки глиомы (GL261), стабильно экспрессирующие еGFP, были предварительно привиты благодаря реализации черепного окна, как описано в [31] и проиллюстрировано на рис. 5а. Организация кортикальных кровеносных сосудов развивается вокруг опухолевых клеток и отслеживается в течение нескольких недель благодаря второму флуорофору, Texas $\operatorname{Red}^{\circledR}-$ конъ- $^{\circledR}$ югированный декстран (70 кД), введенному в хвостовую вену. Фильтры высоких и низких частот (рис. 1А) выбираются таким образом, чтобы обеспечить спектр возбуждения, имеющий форму, которая лучше всего соответствует сумме и максимумам спектров ДФП (рис. 1b).

Спектр ДФП Texas $\operatorname{Red}^{\circledR}$ центрирован на 790 нм [27], против 940 нм для еСFР [26]. ФКВ обнаруживается соответственно в диапазонах 580-700 нм и 490-540 нм. Оптическая мощность и время пребывания пикселя такие же, как и в части 3. На рис. 5b показано результирующее изображение, полученное через 26 с при 200 мкм под поверхностью мозга, через пять дней после процедуры трансплантации. В то время кровеносные сосуды еще не были локализованы совместно с опухолевыми клетками, демонстрирующими низкую васкуляризацию. В ходе эксперимента фотоповреждений не наблюдалось.

Сеть кортикальных кровеносных сосудов, окружающих ксенотрансплантированные опухолевые клетки, хорошо видна. Таким образом, применимость источника CK-лазера для визуализации ФКВ показана в присутствии двух флуорофоров со спектрами ДФП, разделенными 150 нм и покрытыми полосой пропускания 300 нм СК. В нынешней структуре микроскопа биологическая характеристика образца ограничена только двумя имеющимися ФЭУ. С большим количеством детек- 


\section{Наносекундные Nd:YAG лазерные системы серии Q-Smart от Quantel Laser (LUMIBIRD)}

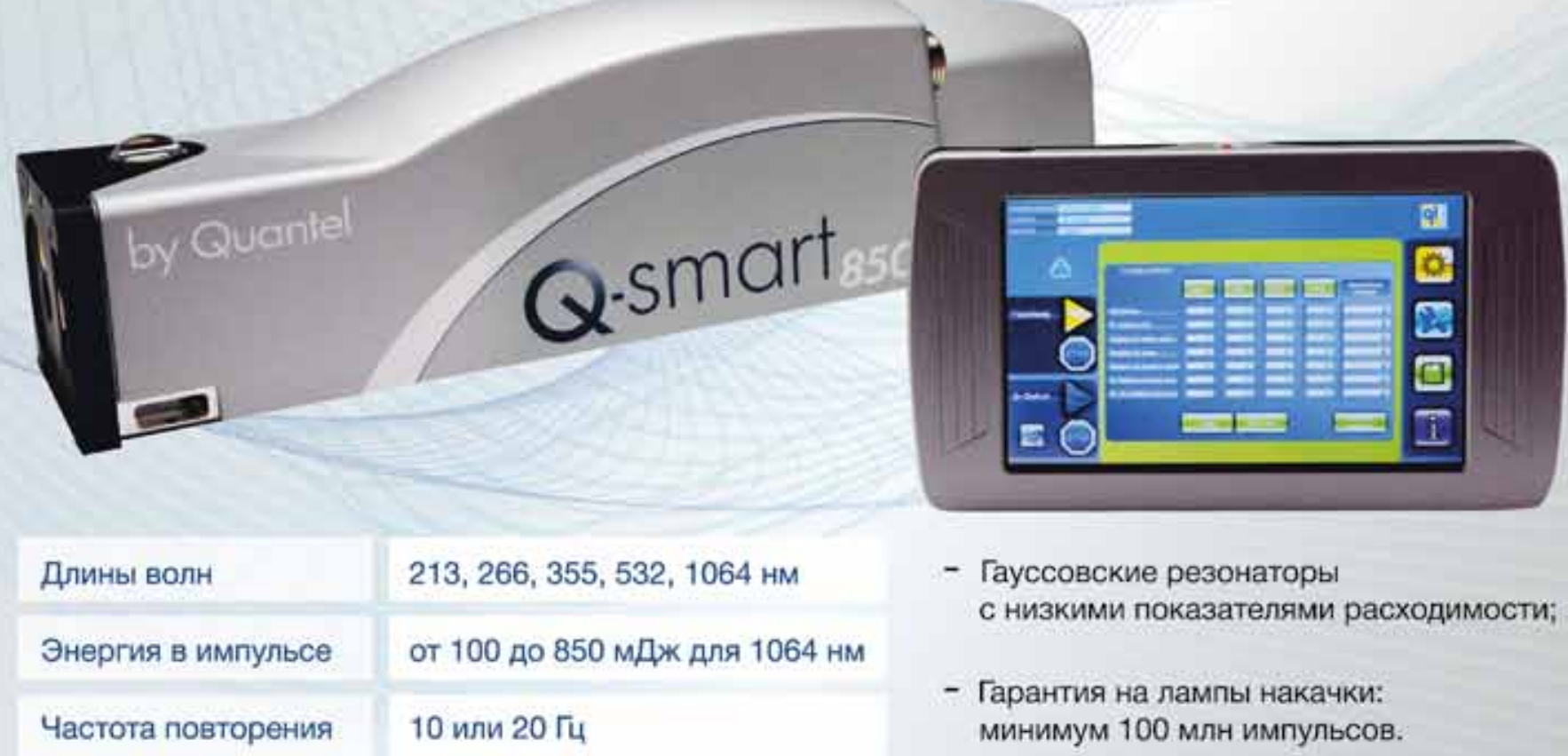

Дополнительное оборудование и опции для научных исследований

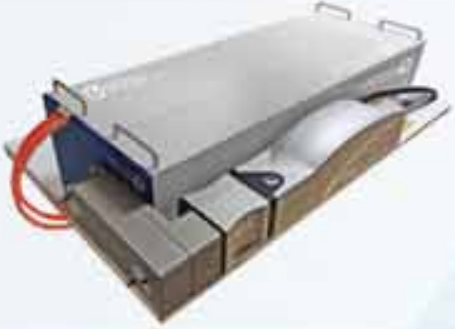

Лазеры

на красителях

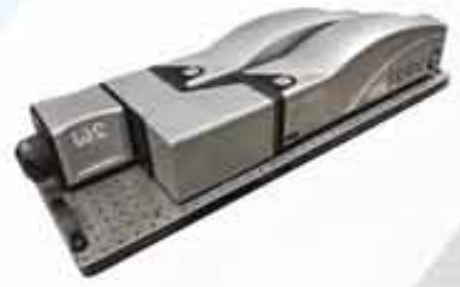

Q-smart с двойным импульсом

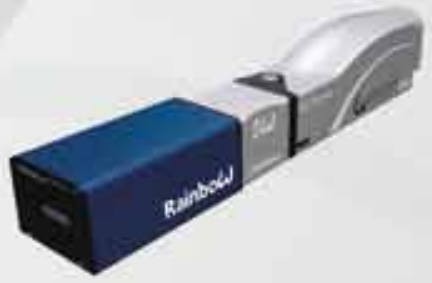

Оптические параметрические генераторы спешиальные системы

ФOTOHИKA
Сертифицированный сервисный центр установка, техническое сопровождение пост-гарантийное обслуживание лазерных систем

\section{ЭКСКЛЮЗИВНЫЙ ДИСТРИБЬЮТОР КОМПАНИИ LUMIBIRD В РОССИИ}

Посетите наш онлайн-каталог на сайте www.sphotonics.ru c технической информацией на русском языке. Получите более подробную информацию, связавшись с нами любым удобным для Вас способом.
$8(800) 550-72-97$
info@sphotonics.ru
www.sphotonics.ru
r, Санкт-Петербург 


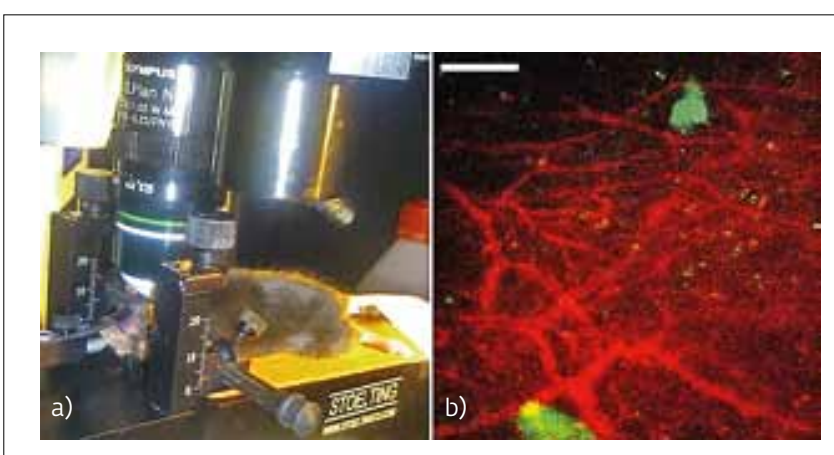

Puc. 5. Визуализация мозга мыши: (a) установка для визуализации мозга мыши in vivo; (b) изображение ДФФ (512×512 пикселов, 100 мкс / пиксел) живого мозга мыши с привитыми опухолевыми клетками, экспрессирующими еGFP (зеленый) и окруженными сетью кровеносных сосудов, маркированных Texas Red ${ }^{\circledR}$ conjugated Dextran (красный). Масштаб: 100 мкм.

торов можно было бы вести характеристику большего числа биологических компонентов или функций. Более быстрое изображение ( 1 кадр/с) с тем же источником СК на 250 кГц должно быть возможным за счет уменьшения времени пребывания пикселя до 4 мкс.

\section{6. ЗАКЛЮЧЕНИЕ И ПЕРСПЕКТИВЫ}

Впервые экспериментально показано, что наносекундный источник СК с низкой частотой повторения пригоден для получения изображений МФМ и особенно ДФФ и ГВГ со сравнимым качеством изображения с классическим Ti:Sa лазером. Изображения мышечной ткани и мозга мышей in vitro и in vivo получали путем соединения наносекундного СК-лазера 250 кГц с обычным многофотонным микроскопом. Использование этого источника вдвойне оправдано и доказано. Во-первых, их широкий спектр позволяет одновременное возбуждение нескольких флуорофоров со спектрами ДФП, охватывающими несколько сотен нм. Во-вторых, технологическая простота лазера с низкой скоростью и наносекундной длительностью позволяет создать новый способ МФМ с источником, обладающим высокой компактностью, высокой надежностью, низкой стоимостью и не требующим технического обслуживания.

Помимо этих аспектов интерес к использованию такой лазерной технологии заключается в ее универсальности, с доступной спектральной полосой от видимого до глубокого БИК спектра. Наряду с этим мультифотонные механизмы более высокого порядка могут быть доступны благодаря боль- шим длинам волн, непосредственно доступным от источника СК. Таким образом, обширный биологический анализ может быть проведен с помощью стабильной и готовой системы микроскопии.

\section{БЛАГОДАРНОСТЬ}

Это исследование было поддержано программой Defi Imag'in от CNRS для проекта AR-KENCIEL в регионе Лимузен с тематическим заданием для проектов. Мы особенно благодарим Фабьен Барэж и Дениз О’Коннор за их техническую помощь в подготовке образцов и мышей.

\section{REFERENCES}

1. Denk W., Strickler J.H., Webb W.W. Science. 248, 4951 (1990).

2. H. Segawa, Y. Kaji, P. Leproux, V. Couderc, T. Ozawa, T. Oshika, and H. Kano. J. Biophotonics. 8 (9) 705-713 (2015).

3. M.J. Booth and S.W. Hell. Journal of Microscopy. 190 (3), 298-304 (1998).

4. J. Bewersdorf and S. W. Hell. Journal of Microscopy. 191 (1), 28-38 (1998).

5. W. Denk, D.W. Piston, and W.W.Webb. Handbook of Biological Confocal Microscopy, Third Edition. 535-549 (2006).

6. A. M. Larson. Nature Photonics 5, doi: 10.1038/nphoton.an.2010.2 (2011).

7. J. Klein and J. D. Kafka. Nature Photonics. 4, 289 (2010).

8. H. Segawa, M. Okuno, P. Leproux, V. Couderc, T. Ozawa, and H. Kano. Analytical Sciences. 31 (2015)

9. D. Vucinic and T.J. Sejnowski. PLos One. 8 (2007).

10. H.J. Koester, D. Baur, R. Uhl, and S. W. Hell. Biophysical Journal. 77, 2226-2236 (1999).

11. M. Baumgart, T. Gottschall, J.Abreu-Afonso, A. Díez, T. Meyer, B. Dietzek, M. Rothhardt, J. Popp, J. Limpert, and A. Tünnermann. Optics Express. 20 (19), 21010-21018 (2012)

12. M. Baumgartl, M. Chemnitz, C. Jauregui, T. Meyer, B. Dietzek, J. Popp, J. Limpert, and A. Tünnermann. Optics Express. 20 (4), 4484-4493 (2012).

13. G. McConnell and E. Riis. Journal of Biomedical Optics. 9 (5), $922-927$ (2004).

14. C. Lefort, M. Kalashyan, G. Ducourthial, T. Mansuryan, R. P. O'Connor, F. Louradour. Journal of Optical Society of America. B31 (10) $2317-2324$ (2014).

15. J.A. Palero, V. O. Boer, J.C. Vijverberg, and H. C. Cerritsen. Opt. Exp. 13, 14 (2005).

16. J.Tada, T. Kono, A. Suda, H. Mizuno, A. Miyawaki, K. Midorikawa, and F. Kannari. Applied Optics. 46 (15), 3023-3030 (2007).

17. X. Liu, J. Lægsgaard, U. Møller, H. Tu, S. A. Boppart, and D. Turchinovich. Optics Letters. 37 (13), 2769-2771 (2012).

18. K. Isobe, W. Watanabe, S. Matsunaga, T. Higashi, K. Fukui, and K. Itoh.Japanese Journal of Applied Physics. 44 (2), 1-7 (2005).

19. D. Li, W. Zheng, and J.Y. Qu. Opt. Lett. 34, 2 (2009).

20. W.Tao, H. Bao, and M. Cu. Journal of Biomedical Optics, 16 (5), 056010 (2011).

21. X. Liang and L. Fu. IEEE Journal of Selected Topics in Quantum Electronics. 20 (2), 6800108 (2014).

22. H. Yokoyama, H. Tsubokawa, H. C. Guo, J. Shikata, K. Sato, K. Takashima, K. Kashiwagi, N. Saito, H. Taniguchi, and H. Ito. J. Biomed. Opt. 12, 5 (2007).

23. D. Jones, J. Round, and A. de Haan. Muscle from Molecules to Movement. -Churchill Livingstone: Elsevier Limited. Oxford (2004).

24. C. Odin, T. Guilbert, A. Alkilani, O. P. Boryskina, V. Fleury, and Y. Le Grand. Opt. Exp. 16 (20), 16151-16165 (2008).

25. J. Mütze, V. Iyer, J.J. Macklin, J. Colonell, B. Karsh, Z. Petrasek, P. Schwille, L. L. Looger, L. D. Lavis, and T. D. Harris. Biophys. J. 102, 934 (2012).

26. Developmental Resource for Biophysical Imaging Opto-Electronics, http://www. drbio.cornell.edu/cross_sections.html, Cornell University.

27. K. G. Heinze, A. Koltermann, and P. Schwille. PNAS97 (19), 10377-10382 (2000)

28. M. Andreana, A. Labruyère, A. Tonello, S. Wabnitz, P. Leproux, V. Couderc, C. Duterte, A. Cserteg, A. Bertrand, Y. Hernandez, D. Giannone, S. Hilaire, and G. Huss. Opt. Exp. 20 (10), 10750-10760 (2012).

29. D.V. Skryabin and A.V. Yulin. Phys. Rev. E72, 016619 (2005).

30. E. Räikkönen, G. Genty, O. Kimmelma, M. Kaivola, K. P. Hansen, and S. C. Buchter. Opt. Exp. 14 (17), 7914-7923 (2006).

31. L. Sacconi, R. P. O'Connor, A. Jasaitis, A. Masi, M. Buffelli, and F. S. Pavone, J. Biomed. Opt. 12, 050502 (2007). 
Фирма «Тэйлор Хобсон Лтд.» Основана в 1886 году и уже более ста лет остается синонимом слова «точность». Сегодня «Тэйлор Хобсон Лтд.» производит самые точные в мире приборы для контроля параметров отклонения от круглости, шероховатости/профиля и расположения поверхностей. Фирма известна и как производитель ультра-прецизионных электро-оптических приборов, электронных уровней и приборов для контропя компонентов прецизионной оптики и сверхгладких поверхностей.

Московское бюро фирмы «Тэйлор Хобсон Лтд.», открытое в 1992 году, призвано удовлетворять потребность российских производственных и научно-исследовательских предприятий в прецизионных приборах фирмы. В рамках заключенного, с головным предприятием Ростехрегулирования - ФГУП «ВНИИМС», соглашения о научно-техническом сотрудничестве, фирма осуществляет техническую поддержку государственных эталонов РФ, в основе которых, используются приборы «Тэйлор Хобсон Лтд.»

Специалисты бюро выполняют работы по вводу оборудования в эксплуатацию, поверке приборов и образцовых мер, проводят обучение операторов заказчика, осуществляют гарантийное и послегарантийное обслуживания приборов. Подобные работы московское бюро предлагает и для предприятий Бепоруссии, Украины, Казахстана и других государств бывшего СССР.

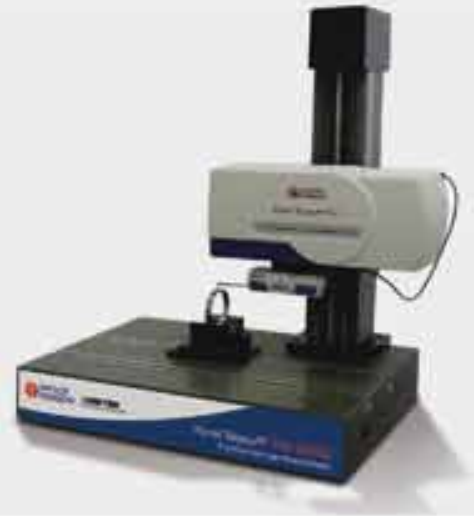

Система дия контроля подиииников Form Talysurf PGI

Измерительная система для контроля деталей подшипников и детапей спохной формы, требующих высоко розрешения при контроле чистоты поверхности и отклонения ог заданной формы.

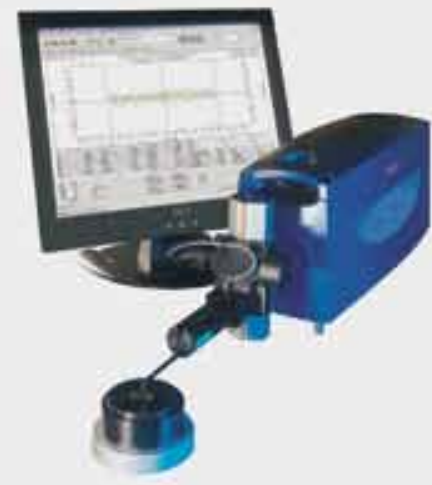

Форм Таписурф Имтра

Цеховой / Лабораторный прибор для измерения параметров шероховотости и волнистости на прямых, сферических вытнутых/вопнутых поверхностяк. Измерения радиуса дуги, углов нокпона профиля, линейных размеров no nosepxности профипя.

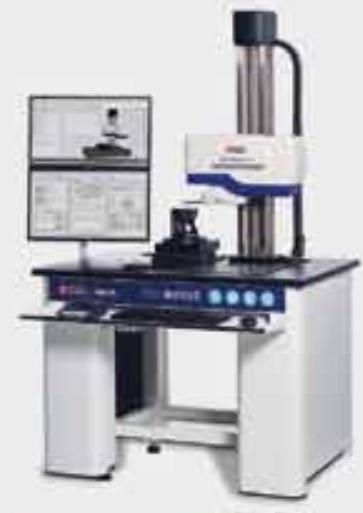

3D профипометр PGI NOVUS

30 профилометр для измерения угпа, шероховотости поверхности, геометрии. В основе разроботки - новаторский двойной датчик смещения.

Датчик NOVUS обеспечивает спосо6. ность измерить диометр, yron, качество обработки поверхности в нормапьном и перевернутом попожении детали с достоточно схоростью и точностью

Enaroдаря этой разработке Taylor Hobson pewaer проблемы, с которыми ежедневно стапкиваются производитепе подшипникоеой и двитатепьной промышпенности, а так же производитепи прецизионных компонентов.

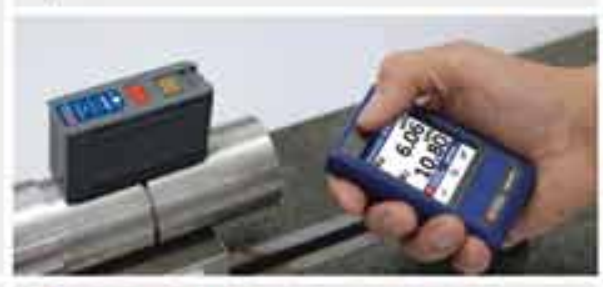

Суртроник Дуо

Суртроник Дуо предназначен для точной оченки параметров шероховатости детапи непосредственно на месте ее изготовления нажатием одной кнопки, за считанные секунды.

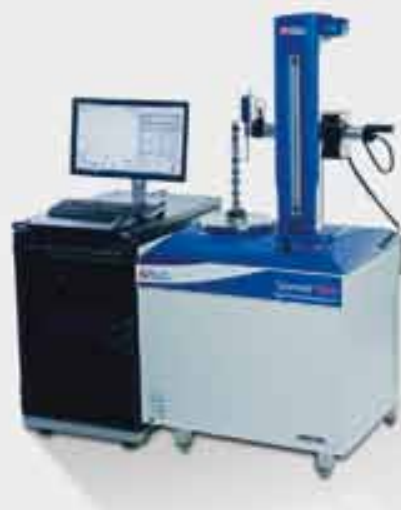

Talyrond

Талиронд воспроияводит форму детали, использун замеры по окружности, вертикапи и горизонтали. Возможность измерение контура и шероховатости.

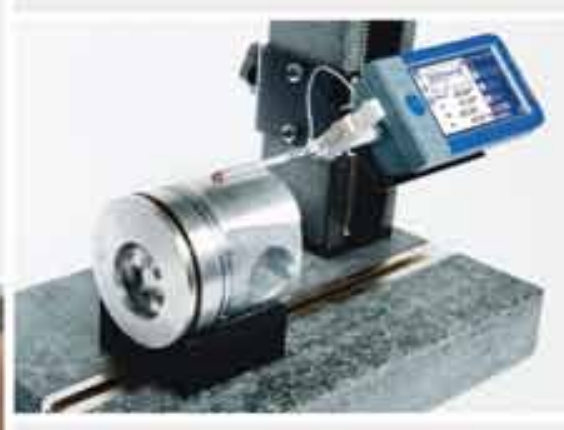

Суртроник S серии

Прибор для измерения параметров шероховатости поверхности спожных детапей в цеховых и лабораторных уеловиях С максимальной производитепьностью и удобством в испопьзовании

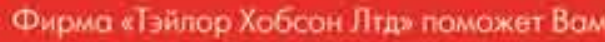
в решіении пробпем обеспечения кочестве продукции. Обращайтесь $\mathrm{k}$ нам с вошими специфическими зодомоми и мы предоставим Вам возможное решение: 